\title{
For Future Athletic Success Work Attitude Capacity and Sport Learning Capacity in Experts' Perceptions Most Important in 6 - 8 Year Olds
}

\author{
Sebastiaan W. J. Platvoet1*, Marije T. Elferink-Gemser², Chris Visscher² \\ ${ }^{1}$ Sport \& Exercise Studies, HAN University of Applied Sciences, Nijmegen, The Netherlands \\ ${ }^{2}$ Center for Human Movement Sciences, University Medical Center Groningen, University of Groningen, Groningen, The Netherlands \\ Email: ^Sebastiaan.Platvoet@han.nl
}

How to cite this paper: Platvoet, S. W. J., Elferink-Gemser, M. T., \& Visscher, C. (2018). For Future Athletic Success Work Attitude Capacity and Sport Learning Capacity in Experts' Perceptions Most Important in 6 - 8 Year Olds. Psychology, 9, 28852895.

https://doi.org/10.4236/psych.2018.914167

Received: November 7, 2018

Accepted: December 21, 2018

Published: December 24, 2018

Copyright $\odot 2018$ by authors and Scientific Research Publishing Inc. This work is licensed under the Creative Commons Attribution International License (CC BY 4.0).

http://creativecommons.org/licenses/by/4.0/

\begin{abstract}
Purpose: To identify whether experts' perceptions of future athletic success in six- to eight-year-old children is related to the type of sport (i.e., teamopen versus individual-closed). Methods: 114 physical education experts (Mage $=41.4, S D=13.2)$ in team-open $(n=63)$ or individual-closed sports $(n$ $=51$ ) filled in the Scale for Identification of Sport Potential (SISP). Results: Rankings of capacities in team-open sports resembled those in individual-closed sports with work attitude and sports learning capacity on top. A MANOVA showed a difference in perceptions of capacities for future sports success in team-open versus individual-closed sports $(\mathrm{F}[6,108]=13.97, p$ $<.05$, Wilks' Lambda $=.563$ ) on three scales. While motor capacity was scored lower for team-open sports, interpersonal and intellectual capacity were scored higher than for individual-closed sports $(p<.05)$. No differences were found for work attitude, sports learning, and creative capacity, or on overall score $(p>.05)$. Conclusion: Regardless of the type of sport, experts rank work attitude capacity and sports learning capacity as most important in early childhood athlete identification processes. This supports more general sports and physical education program contents for young children.
\end{abstract}

\section{Keywords}

Team-Open Sports, Individual-Closed Sports, Early Childhood, Physical Education, SISP, Identification

\section{Introduction}

To better understand the effectiveness of talent identification, it is important to 
determine the factors that influence skill development (Baker, Hodges, \& Wilson, 2018). This is especially important for children at a young age as most studies on talent identification focused on children above age ten (Johnston, Wattie, Schorer, \& Baker, 2018) Physical education (PE) offers unique opportunities for the youngest age groups since school PE classes provide the first structured environment that enables many young children to develop the capacities to become successful in sports (i.e., perform at the highest national level) (Gulbin, Oldenziel, Weissensteiner, \& Gagné, 2010; Platvoet, Elferink-Gemser, Baker, \& Visscher, 2015). In their early school years, children develop motor and psycho-social performance development capacities that help them learn and improve sport-specific skills at a later age (Clark, 2007; Kirk \& Gorely, 2000). Given their specific qualifications, PE teachers might even represent a major front-line force in the initial assessment of children who might become successful athletes (Bailey \& Morley, 2006; Gulbin et al., 2010; Platvoet et al., 2015). Many PE teachers also have a coaching background that contributes to their expertise in developing children's skills in sports. This study focuses on experts' (i.e., PE teachers with a coaching background) perceptions of capacities that enable young children to become successful in team-open and closed-skill sports. Are these capacities similar for different kinds of sports despite performance-related differences between them? The answer to this question is relevant for the content of programs that aim to identify and develop children's sports skills.

Better performance in any sport can largely be attributed to personal performance characteristics like anthropometry (e.g., height, body weight), physiological capacities (e.g., speed, endurance capacity), technical skills (e.g., sport-specific skills), tactical skills (e.g., decision-making, strategy), and psychological skills (e.g., goal setting, coping with stress) (Elferink-Gemser, Jordet, Coeho E Silva, \& Visscher, 2011; Elferink-Gemser, Visscher, Lemmink, \& Mulder, 2004). Since these characteristics are deduced from the sport's requirements (i.e., from match, game, and race analyses), they have a different hierarchy of importance for performance in different sports (Elferink-Gemser et al., 2011).

Based on their requirements, many sports can be clustered into team-open sports or individual-closed sports (Paul \& Nassis, 2015; Taddei, Bultrini, Spinelli, \& Di Russo, 2012). Team-open sports athletes (e.g., soccer, handball, and basketball players) need to react in a dynamically changing, unpredictable, and externally-paced environment to succeed (Paul \& Nassis, 2015). In contrast, individual-closed sports (e.g., gymnastics, speed skating, and track and field) are characterized by a relatively consistent, more predictable and self-paced environment (Singer, 2000). In individual-closed sports, athletes themselves are solely responsible for their performance and a relatively smaller number of characteristics may account for performance variance compared with team-open sports (Vaeyens, Lenoir, Williams, \& Philippaerts, 2008).

When working with children, however, one needs to remember that what characterizes a champion may not be similar to what is required to become a 
champion (Elferink-Gemser \&Visscher, 2012; Phillips, Davids, Renshaw, \& Portus, 2010). The Differentiated Model of Giftedness and Talent (DMGT) (Gagné, 2010) and the Model of Talent Identification in Physical Education (Bailey \& Morley, 2006) emphasize the importance of intrapersonal catalysts for effective and efficient talent development of a child's athletic career. Capacities that enable young children to become successful in sports may prove to be equally or even more meaningful than sport-specific performance characteristics at a young age. Many of the latter can be developed with appropriate training opportunities and are usually only partly apparent at a young age (Abbott \& Collins, 2004; Gulbin et al., 2010; Opstoel et al., 2015). In a recent review about talent identification, Johnston et al. (2018) revealed that little is known about the capacities of children under the age of ten and more research is needed.

Platvoet et al. (2015) developed the Scale for Identification of Sport Potential (SISP), which includes both motor and psycho-social performance development capacities. The SISP is the first step towards a reliable and valid assessment tool for initial assessment of athletic potential in children aged six to eight years. According to PE teachers, a child with the potential to become an elite athlete excels in six capacities (i.e., work attitude, sports learning, motor, creative, interpersonal, and intellectual) (Platvoet et al., 2015). However, it is unknown whether these capacities have different meanings for different types of sports. If so, one may want to consider developing different identification and development programs for children playing different sports. If not, a more general program may prove the better choice for young children, even when advocating later specialization in one specific sport. Therefore, this study was conducted with the main aim of identifying whether experts' perceptions of future athletic success in six- to eight-year-old children is related to the type of sport (i.e., teamopen sports versus individual-closed sports).

\section{Method}

\subsection{Sample}

58 male and 56 female experts with teaching expertise in physical education and sports (Mage $=41.4, S D=13.2$ ) participated in this research. Based on their specific expertise, we divided the participants into two groups. The first had expertise as coaches in a team-open sport such as soccer, field hockey, basketball, or handball ( $n=63$, of which 38 male and 25 female). The second group had expertise as coaches in a closed-individual sport like gymnastics, track and field, or swimming ( $n=51$, of which 20 male and 31 female). All participants had qualifications in their sport (i.e., were certified or officially licensed by their sports union or government) and a bachelor in physical education, and worked in PE with children between six and eight years of age during the study.

\subsection{Procedure}

The Dutch Union of Physical Education sent an email to PE teachers who work 
in primary education. That email contained a hyperlink to the digital questionnaire. For data collection, we used secure sockets layer (SSL) technology and ensured the privacy and security of the data for all participants. The sampling process resulted in a representative group of PE teachers with expertise and qualifications in team-open and individual-closed sports in the Netherlands. The following inclusion criteria were used for team-open sports: ball sport, more than two members, open and dynamic character, and interrelated relationships. The following inclusion criteria were used for individual-closed sports: the athlete is solely responsible for their performance, performance is predictable, and it occurs in a self-paced environment. The study fits the established ethical standards for sports medicine (Harris \& Atkinson, 2011). Institutional approval was obtained from the research advice board.

\subsection{Questionnaire}

We used the SISP questionnaire to identify experts' perceptions in team-open and individual-closed sports (Platvoet et al., 2015). The SISP is based on Bailey and Morley's (2006) Model of Talent Development in PE. The questionnaire consists of 27 items, which relate to the six capacities that PE teachers believe characterize children with the capacity to become elite athletes (i.e., to perform at a national level). They are work attitude capacity (e.g., always tries to do their best, is goal oriented), sports learning capacity (e.g., rapidly acquires exercise skills, likes to learn new movements), motor capacity (e.g., good balance skills, jump capacity), creative capacity (e.g., uses original solutions to movement problems), interpersonal capacity (e.g., can make classmates enthusiastic, often takes the lead in group work), and intellectual capacity (e.g., highly intelligent, among the smartest students in class). We asked respondents to fill in the questionnaire for their own sport. The specific response stem for the experts was: "A 6- to 8-year-old with the capacity to become an elite athlete in the future in... (fill in your own sport) is a child who..." followed by the list of 27 items. Respondents scored their level of agreement on a five-point scale $(1=$ strongly disagree to $5=$ agree very much). The reliability and internal validity of the SISP was confirmed with Cronbach's a ranging from .73 to .87; ICCs of the capacities varied between .71 and .90 (Platvoet et al., 2015).

\subsection{Statistical Analyses}

All data were analyzed using SPSS v.17.0. We calculated capacity scores by summing the scores of the individual items and dividing that sum by the number of items. We then calculated descriptive statistics to determine absolute differences of the six capacities between team-open and individual-closed sports for children aged six to eight years. Data were normally distributed among each capacity. Effect sizes $(r)$ were calculated, with .10 indicating a small effect, .30 a medium effect, and .50 a large effect (Cohen, 1992).

Paired sample $t$-tests were used to look for differences in ranking of the capacities between experts' perceptions of children with the capacity to become elite 
athletes in team-open and individual-closed sports. The first step was to compare the two capacities with the highest score within team-open sports. If we found no significant difference, the capacity with the highest score was compared with the capacity with the third highest score. If we found a significant difference in the next analysis, this capacity was compared with capacities with lower scores. The same procedure was followed for individual-closed sports scores. Significance level was set at $p<.05$.

We used a MANOVA with a Bonferroni correction for multiple comparisons to keep the alpha level below .05 and determine differences between team-open and individual-closed sports. The six capacities were dependent variables. The significance level was set at $p<.05$.

In addition, we performed an independent $t$-test to determine if a significant difference exists between experts' perceptions of children with the capacity to become elite athletes in team-open and individual-closed sports on the overall score on the SISP (i.e., the sum of the score of the six capacities). The significance level was set at $p<.05$.

\section{Results}

Table 1 shows descriptive statistics about the six capacities that describe experts' perceptions of six- to eight-year-old children with the capacity to become elite athletes in team-open and individual-closed sports.

\subsection{Ranking}

Table 2 shows the ranking of the capacities in team-open and individual-closed sports. In team-open sports, paired sample $t$-tests showed that the work attitude capacity score is significantly higher than the motor capacity score $(t(63)=3.90$, $p<.025, r=.27)$. In turn, the motor capacity score is significantly higher than the intellectual capacity score $(t(63)=7.14, p<.025, r=.51)$. Therefore, in experts' perceptions, work attitude and sports learning are the most significant capacities for predicting whether a child could become an elite athlete in team-open sports. Motor, creative and interpersonal capacities are next in significance, and intellectual capacity is the least significant.

In individual-closed sports, paired sample $t$-tests showed that the work attitude score is significantly higher than the creative capacity score $(t(50)=7.01, p$ $<.025, r=.57)$. Creative capacity was scored higher than interpersonal capacity $(t(50)=7.24, p<.025, r=.49)$. Therefore, in experts' perceptions, work attitude, sports learning, and motor capacities are the most important for predicting whether a child could become an elite athlete in individual-closed sports. Creative capacity is next in significance, and interpersonal and intellectual capacities were the least significant.

\subsection{Significance of Each Capacity}

After correction for multiple tests, the MANOVA results showed a significant 
Table 1. Experts' perceptions in team-open and individual-closed sports on the SISP.

\begin{tabular}{cccccccc}
\hline & \multicolumn{2}{c}{$\begin{array}{c}\text { Team-open } \\
(\mathrm{n}=63)\end{array}$} & \multicolumn{2}{c}{$\begin{array}{c}\text { Individual-closed } \\
(\mathrm{n}=51)\end{array}$} & & & \\
\hline & $\mathrm{M}$ & $\mathrm{SD}$ & $\mathrm{M}$ & $\mathrm{SD}$ & $\mathrm{F}$ & $p$ & $r$ \\
\hline Work attitude & 4.35 & .56 & 4.59 & .43 & 7.24 & .013 & -.23 \\
Sports learning & 4.37 & .43 & 4.54 & .27 & 9.35 & .016 & -.23 \\
Motor & 4.04 & .54 & 4.45 & .59 & 22.44 & $<.001^{*}$ & -.34 \\
Creative & 3.96 & .67 & 3.80 & .69 & 2.90 & .191 & .12 \\
Interpersonal & 3.81 & .62 & 3.06 & .61 & 19.86 & $<.001^{*}$ & .52 \\
Intellectual & 3.27 & .72 & 2.86 & .74 & 12.97 & $.003^{*}$ & .27 \\
\hline
\end{tabular}

${ }^{*} p<.05$ after Bonferroni correction.

Table 2. Ranking of the six capacities of the SISP for team-open and individual-closed sports.

\begin{tabular}{cc}
\hline Team-open sports & Individual-closed sports \\
\hline Sports learning capacity & Work attitude capacity \\
Work attitude capacity & Sports learning capacity \\
Motor capacity & Motor capacity \\
Creative capacity & Creative capacity \\
Interpersonal capacity & \\
Intellectual capacity* & Interpersonal capacity \\
& Intellectual capacity \\
\hline
\end{tabular}

Note $1 .{ }^{*}$ Paired sample t-tests showed that this capacity has a significantly lower score than the capacities above $(p<.05)$.

difference between experts' perceptions in team-open and individual-closed sports $(\mathrm{F}[6,108]=13.97, p<.05$, Wilks' Lambda $=.563)$. The univariate analyses of variance revealed that experts ranked motor capacity higher in individual-closed sports $(M=4.54, S D=.59)$ than in team-open sports $(M=4.04, S D$ $=.54), \mathrm{F}[1,113]=15.31, p<.05, r=-.34$. They also ranked interpersonal capacity higher in team-open sports $(M=3.81, S D=.62)$ than in individual-closed sports $(M=3.06, S D=.61), \mathrm{F}[1,113]=42.27, p<.05, r=.52$. Intellectual capacity also scored higher in team-open sports $(M=3.27, S D=.72)$ than in individual-closed sports $(M=2.86, S D=.74), \mathrm{F}[1,113]=42.27, p<.05, r=.27$. We found no significant differences for work attitude capacity, sports learning capacity, or creative capacity $(p>.05)$. See Table 1 .

\subsection{Overall Score on the SISP}

The independent sample $t$-test showed no significant difference between experts' perceptions on the overall SISP score for team-open sports $(M=23.8, \mathrm{SD}=2.4)$ and individual-closed sports $(M=23.3, S D=1.9), t(113)=1.25, p>.05, r=.12$.

\section{Discussion}

The main aim of this study was to identify whether experts' perceptions of future 
athletic success in six- to eight-year-old children is related to the type of sport (i.e., team-open versus individual-closed). The results show that regardless of the type of sport, experts perceived the work attitude and sports learning capacities to be the most important for identifying children who might become successful athletes.

Experts' perceptions were compiled using the SISP, which contains 27 items divided over six subscales (Platvoet et al., 2015). The participants were experienced PE teachers with unique knowledge and expertise about the development of young children. Their coaching work in team-open or individual-closed sports ensured that they understood what is necessary to excel in those sports. The participants' educational backgrounds seem to explain the high scores assigned to work attitude capacity and sports learning capacity. Apparently, highly educated coaches of various sports recognize the importance of capacities that express a child's ability to become successful rather than focusing primarily on their current performance (Abbott \& Collins, 2004; MacNamara, Button, \& Collins, 2010; Platvoet et al., 2015).

In experts' perceptions, creative capacity has a similar significance in team-open and individual-closed sports. This might be explained by the items that underlie the creative capacity, which express a child's ability to solve movement problems, rather than more sport-specific tactical skills, which are directly related to performance in team-open sports (Memmert \& Roth, 2007). The different scores for team-open and individual-closed sports on motor capacity, interpersonal capacity, and intellectual capacity may be explained by the requirements of the sport, which are well known by the participants in this study (Elferink-Gemser \& Visscher, 2012). In individual-closed sports, athletes are solely responsible for their performance, so it is reasonable to expect that motor capacity is more significant in individual-closed sports than in team-open sports (in which athletes have more opportunities to compensate) (Vaeyens et al., 2008). In team-open sports, athletes are more dependent on their environment for performance and development (see the DMGT 2.0) (Gagné, 2010), which might explain this difference in experts' perceptions about interpersonal capacity. Interpersonal capacity generally reflects a capacity to positively influence the social environment (Platvoet et al., 2015). The higher significance of intellectual capacity in team-open sports may be explained by the higher perceptual-cognitive demands of this type of sport (Taddei et al., 2012). This is supported by a study that found that 14- to 17-year-old elite youth soccer players outperform sub-elite youth soccer players on metacognition, inhibitory control, and cognitive flexibility, and generally complete a higher level of education (Huijgen et al., 2015). However, there appear to have been no extensive studies of differences in intellectual capacity between talented or elite athletes in different types of sports. Further research is needed to better understand identification and development processes related to intellectual capacity.

Following Gagné's DMGT (Gagné, 2010), around 10\% of children have the 
potential to develop into talented athletes. A good understanding of the capacities that characterize these children could improve talent identification and talent development programs (Baker et al., 2018; Vaeyens et al., 2008). In sports, a one-dimensional approach is most often used to assess children. It is expected that such an approach would result in many children being overlooked (Abbott \& Collins, 2004; Gray \& Plucker, 2010). This seems to be confirmed by the findings of Johnston et al. (2018) review of the past 25 years of research on talent identification. They concluded that there is much to be learned and that a more diverse approach to research is needed. The development of the SISP and the results of this study offer PE teachers the first steps towards a reliable and valid tool. This may optimize their role and improve current processes of initial assessment (Gulbin et al., 2010), especially as the SISP stimulates a multidimensional approach with a strong emphasis on psycho-social capacities, whose relevance has been highlighted in several studies (MacNamara et al., 2010; Van Yperen, 2009). Further studies should focus on the predictive value of the SISP with large and diverse samples followed from a young age.

The results of this study could be used to draft recommendations for professionals who work with children that might succeed in sports. Since the experts' ranking of the most important capacities is similar for different types of sports, there is no support for early specialization in this respect. Rather, general programs focusing on psycho-behavioral and motor capacities seem suitable for young children aged six to eight years. High levels of work attitude capacity and sports learning capacity are important to being perceived as a child who could succeed in team-open or individual-closed sports. It is advised that teachers pay attention to these capacities in programs, for identification and development purposes (Johnston et al., 2018). The SISP can be used by teachers as a tool for initial assessment of children who might succeed in sport. Still, the results of this study also justify to differ in identifying children for team-open and individual-closed sports. In addition to high scores on work attitude and sport learning capacity, for individual-closed sports children characterize themselves by high levels of motor capacity, whereas for team-open sports children are more characterized by higher levels of interpersonal and intellectual capacity, i.e., for talent detection purposes (Vaeyens et al., 2008). This knowledge could be used to help children in their search for the sport they would like to develop in most. However, we believe that identification of children's capacities at a young age should not be used for early selection in one specific sport. Instead, we advise providing children with age-related programs that meet their developmental demands and interests.

This study has a limitation that also needs to be addressed. It is uncertain whether the participants' perceptions are valid, since nolongitudinal studies have been conducted to validate them. However, most of this study's participants had worked for many years with young children in a physical education setting and had experience as a coach in team-open or individual-closed sports. As such, it 
seems reasonable to assume that they can characterize children with the capacity to become an elite athlete in their own sport. The results are also in line with those of other studies, suggesting that it may be a good idea for those involved with young children to examine their working attitude and sports learning capacities (Abbott \& Collins, 2004; Bailey \& Morley, 2006; Platvoet et al., 2015). To take this one step further, we recommend that future researchers developa tool with which children can be monitored over time in a longitudinal design.

\section{Conclusion}

In summary, our results showed that experts with experience in PE and as coaches in team-open or in individual-closed sports similarly ranked capacities that enable children to become successful in sports regardless of the type of sport. Capacities that are most important to a child's ability to become a successful athlete (i.e., work attitude capacity, sports learning capacity) have the same significance in team-open and individual-closed sports. Motor capacity, interpersonal capacity, and intellectual capacity have different significance when identifying young children who could become successful in team-open sports and individual-closed sports. Raising awareness of the SISP and the results among professionals who work with young children could offer them unique opportunity to learn and to improve their ability to identify potential athletes and better develop their capacities in physical education and sports.

\section{Conflicts of Interest}

The authors declare no conflicts of interest regarding the publication of this paper.

\section{References}

Abbott, A., \& Collins, D. (2004). Eliminating the Dichotomy between Theory and Practice in Talent Identification and Development: Considering the Role of Psychology. Journal of Sport Sciences, 22, 395-408. https://doi.org/10.1080/02640410410001675324

Bailey, R., \& Morley, D. (2006). Towards a Model of Talent Development in Physical Education. Sport Education and Society, 11, 211-230. https://doi.org/10.1080/13573320600813366

Baker, J., Hodges, N. J., \& Wilson, M. (2018). Collecting and Assessing Practice Activity Data: Concurrent, Retrospective and Longitudinal Approaches. In K. A. Ericsson, R. R. Hoffman, A. Kozbelt, \& A. M. Williams (Eds.), The Cambridge Handbook of Expertise and Expert Performance (2nd ed., pp. 257-270). Cambridge: Cambridge University Press. https://doi.org/10.1017/9781316480748.015

Clark, J. E. (2007). On the Problem of Motor Skill Development. Journal of Physical Education, Recreation \& Dance, 78, 39-44. https://doi.org/10.1080/07303084.2007.10598023

Cohen, J. (1992). Statistical Power Analysis for the Behavioral Sciences (3rd ed.). New York, NY: Academic Press.

Elferink-Gemser, M. T., \& Visscher, C. (2012). Who Are the Superstars of Tomorrow? Talent Development in Dutch Soccer. In J. Baker, J. Schorer, \& S. Cobley (Eds.), Talent 
Identification and Development in Sport. International Perspectives (pp. 95-105). London: Routledge.

Elferink-Gemser, M. T., Jordet, G., Coeho E Silva, M. J., \& Visscher, C. (2011). The Marvels of Elite Sports: How to Get There? British Journal of Sports Medicine, 45, 683-684. https://doi.org/10.1136/bjsports-2011-090254

Elferink-Gemser, M. T., Visscher, C., Lemmink, K. A. P. M., \& Mulder, T. W. (2004). Relation between Multidimensional Performance Characteristics and Level of Performance in Talented Youth Field Hockey Players. Journal of Sports Sciences, 22, 10531063. https://doi.org/10.1080/02640410410001729991

Gagné, F. (2010). Motivation within the DMGT 2.0 Framework. High Ability Studies, 21, 81-99. https://doi.org/10.1080/13598139.2010.525341

Gray, H. J., \& Plucker, J. (2010). “She’s a Natural”: Identifying and Developing Athletic Talent. Journal for the Education of the Gifted, 33, 361-380. https://doi.org/10.1177/016235321003300304

Gulbin, J. P., Oldenziel, K. E., Weissensteiner, J. R., \& Gagné, F. (2010). A Look through the Rear View Mirror: Developmental Experiences and Insights of High Performance Athletes. Talent Development \&Excellence, 2, 149-164.

Harris, D. J., \& Atkinson, G. (2011). Update-Ethical Standards in Sport and Exercise Science Research. International Journal of Sports Medicine, 32, 819-821. https://doi.org/10.1055/s-0031-1287829

Huijgen, B. C. H., Leemhuis, S., Kok, N. M., Verburgh, L., Oosterlaan, J., ElferinkGemser, M. T., \& Visscher, C. (2015). Cognitive Functions in Elite and Sub-Elite Youth Soccer Players Aged 13 to 17 Years. PLoS ONE, 10, e0144580. https://doi.org/10.1371/journal.pone.0144580

Johnston, K., Wattie, N., Schorer, J., \& Baker, J. (2018). Talent Identification in Sport: A Systematic Review. Sports Medicine, 48, 97-109. https://doi.org/10.1007/s40279-017-0803-2

Kirk, D., \& Gorely, T. (2000). Challenging Thinking about the Relationship between School Physical Education and Sports Performance. European Physical Education Review, 6, 119-133. https://doi.org/10.1177/1356336X000062002

MacNamara, Á., Button, A., \& Collins, D. (2010). The Role of Psychological Characteristics in Facilitating the Pathway to Elite Performance. Part 1: Identifying Mental Skills and Behaviors. The Sport Psychologist, 24, 52-73. https://doi.org/10.1123/tsp.24.1.52

Memmert, D., \& Roth, K. (2007). The Effects of Non-Specific and Specific Concepts on Tactical Creativity in Team Ball Sports. Journal of Sports Sciences, 25, 1423-1432. https://doi.org/10.1080/02640410601129755

Opstoel, K., Pion, J., Elferink-Gemser, M. T., Hartman, E., Willemse, B., Philippaerts, R., Lenoir, M. et al. (2015). Anthropometric Characteristics, Physical Fitness and Motor Coordination of 9 to 11 Year Old Children Participating in a Wide Range of Sports. PLoS ONE, 10, e0126282. https://doi.org/10.1371/journal.pone.0126282

Paul, D. J., \& Nassis, G. P. (2015). Physical Fitness Testing in Youth Soccer: Issues and Considerations Regarding Reliability, Validity and Sensitivity. Pediatric Exercise Sciences, 27, 301-313. https://doi.org/10.1123/pes.2014-0085

Phillips, E., Davids, K., Renshaw, I., \& Portus, M. (2010). Expert Performance in Sport and the Dynamics of Talent Development. Sports Medicine, 40, 271-283. https://doi.org/10.2165/11319430-000000000-00000

Platvoet, S. W. J., Elferink-Gemser, M. T., Baker, J., \& Visscher, C. (2015). Physical Education Teachers' Perceptions of Sport Potential: Development of the Scale for Identifi- 
cation of Sport Potential (SISP). Annals of Research in Physical Activity \& Sport, 6, 63-79.

Singer, R. N. (2000). Performance and Human Factors: Considerations about Cognition and Attention for Self-Paced and Externally-Paced Events. Ergonomics, 43, 1661-1680. https://doi.org/10.1080/001401300750004078

Taddei, F., Bultrini, A., Spinelli, D., \& Di Russo, F. (2012). Neural Correlates of Attentional and Executive Processing in Middle-Age Fencers. Medicine and Science in Sports and Exercise, 44, 1057-1066. https://doi.org/10.1249/MSS.0b013e31824529c2

Vaeyens, R., Lenoir, M., Williams, M., \& Philippaerts, R. (2008). Talent Identification and Development Programmes in Sport: Current Modes and Future Direction. Sports Medicine, 38, 703-714. https://doi.org/10.2165/00007256-200838090-00001

Van Yperen, N. W. (2009). Why Some Make It and Others Do Not: Identifying Psychological Factors That Predict Career Success in Professional Adult Soccer. The Sport Psychologist, 23, 317-329. https://doi.org/10.1123/tsp.23.3.317 